\title{
Culturally Responsive and Anti-Biased Teaching Benefits Early Childhood Pre-Service Teachers
}

\author{
Lydiah Nganga ${ }^{1, *}$ \\ ${ }^{1}$ College of Education, University of Wyoming at Casper, USA \\ *Correspondence: College of Education, University of Wyoming at Casper, P.O. Box 50462, Casper, WY, 82605, \\ USA. Tel: 1-307-268-3042. E-mail: Lnganga@uwyo.edu
}

Received: March 5, $2015 \quad$ Accepted: March 15, $2015 \quad$ Online Published: June 3, 2015

doi:10.5430/jct.v4n2p1 URL: http://dx.doi.org/10.5430/jct.v4n2p1

\begin{abstract}
The purpose of this qualitative study was to examine pre-service teachers' perceptions of a culturally responsive, anti-bias curriculum. Additionally, this study explored how the use of culturally responsive course work influenced the participating pre-service teachers' perceptions. Responses to both pre and post-teaching open ended questions, weekly reflective writings, evaluation of a children's books, and notes from the researcher's observation were analyzed qualitatively. Pre-teaching data showed that pre-service teachers had a rather superficial understanding of an anti-bias curriculum. However, post-teaching data showed that after experiencing culturally responsive curricula, pre-service teachers not only developed a better understanding of anti-bias curriculum, but they also gained essential self-awareness in diversity contexts.
\end{abstract}

Keywords: pre-service teachers; teacher preparation; culturally responsive teaching; cultural diversity; transformative learning; social justice; anti-bias education; early childhood

\section{Introduction}

According to United State of America (U.S.) census data, nearly half of the children currently under the age of five are minorities and no racial or ethnic group will be a majority in the year 2050 (Deruy, 2013). In addition, Deruy, reporting data from the National Center for Education Statistics, stated that students of color made up 45 percent of the population in PK-12. At the same time, only 17.5 percent of educators in the workforce were faculty of color. Despite increasing diversity in the U.S., Deruy argued that formal institutions were still overwhelmingly reliant on the cultural influences from the dominant culture that are largely based on western European values. According to Gollnick and Chinn (2004), for example, the major cultural influence in the U.S. has been white Anglo-Saxon or western European and Protestants (WASP). But Gollick and Chinn postulated, "no longer is the dominant group composed only of WASPs. Instead, most members of the ethnically diverse middle class have adopted these traditionally WASP institutions, which provide the framework for the traits and values that outsiders identify as U.S. culture" (p. 13). Notwithstanding the increasing diversity and cultural influences from numerous groups, most of American institutions (schools, welfare services, banks, government, etc.) still operate under the influence of WASP. For example, the overpowering dominant group's value of individualism, which is the belief that the individual controls his/her destiny, and will advance or regress according to his/her effort (pulling oneself by their bootstraps) ignores the fact that other communities are communitarians, or the believe in working as a social unit. Additionally, individualism ignores the exiting inequalities in the U.S. For example, while most members of the dominant group (White) do not have to think about their race, economic and language privileges, minority groups often have to think about racism, inequality and powerlessness. In education, most teachers are White and middle class and have made "little effort to make inequality, racism, or powerlessness problematic, open to discussion"(Gollnick \& Chinn, 2004, p. 13). Because the dominant group controls the curriculum, the marginalized people are expected to learn the culture and history of the major group, without the opportunity to see or hear themselves or validate their own histories and lived experiences.

The existing power differential in the curricula is a contested area. As a result, many scholars have argued that an education prepares students for quality participation in a diverse democratic society is better than one that maintains the existing societal status quo (Nagda, Kim, \& Truelove, 2004). Nonetheless, many new teachers are ill prepared to 
work effectively in diverse communities (Lenski, Crumpler, Stallworth \& Crawford, 2005). This preparedness can be attributed to factors such as teachers' attitudes and beliefs about working effectively with diverse children and their families (Banks, 2001; Nieto, 2004; Sleeter \& Grant, 1994). Consequently, the success of any quality education program is often mediated by candidates' openness and responsiveness to content that they are exposed to (Causey, Thomas, \& Armento, 2000). To that end, preparing teachers using culturally relevant course work might have a positive influence in teachers' understanding of their students and their lived experiences. Indeed, an education that is culturally responsive plays a critical role in helping teachers to identify, analyze, and reconstruct low expectations, negative stereotypes, and cultural misconceptions (Pohan \& Adam, 2007).

\section{The Role of Early Childhood Teachers in Fostering Positive Identities}

Young children construct their identities based on what they see and hear. For example, children construct their racial identity from their experiences, especially how they are treated by the society. Consequently, the messages and treatment they receive from the larger society communicate to them how their race or those who look like them are treated. A message that is inconsistent with children's home experiences can be confusing, and can have negative effects in their development as well as learning (Derman-Sparks \& Edwards, 2010; Nganga, 2015). As a result, early childhood educators need to pay attention to the lived experiences of the children that they work with because "pretending racial identity doesn't exist or doesn't matter leaves children to find their own way within a system of misinformation, confusion, and injury" (Derman-Sparks \& Edwards, 2010, p. 80). Additionally, children begin to notice differences in skin color from an early age. During pre-school years, for example, they absorb messages about their race, which may lead to feelings of being inferior or superior. The following quote by Derman-Sparks \& Edwards (2010, p. 83) demonstrate this reality rather well:

After being taken to see a popular children's film, 3-year-old Alice says soberly, “I don't like all those dark people." At first, her grandmother is puzzled, as all the animated characters in the film were animals. Then she realizes that all the "good" animals were golden. While her grandmother struggles to think what to say, Alice adds, with relief in her voice, "I'm not as dark as Audra (her older sister)

Creating an environment where children learn and discuss similarities and differences, why people are different and alike, and expanding children's racial awareness is key to helping them develop positive identities. According to Derman-Sparks \& Edwards (2010), for example, children try to make sense of their experiences, and what they hear from others by developing their own theories. These theories are usually incorrect; therefore, teachers of young children play a key role in dispelling them, and guiding children in learning about accurate cultural differences. Subsequently, early childhood educators should implement curricula that promote positive and accurate learning experiences. Such curricula are anti-biased.

Anti-biased teaching focuses on areas of self-awareness. It also seeks to promote a clear understanding of children and their families through the use of materials and instructional strategies that are culturally relevant (Nganga, 2015). Given the benefits of anti-biased curricula, it is critical to expose all pre-service teachers with pertinent knowledge and skills. An essential skill, for example, is the ability to support the learning needs of all children, regardless of their cultural and linguistic backgrounds (Laughlin \& Nganga, 2009). While Derman-Sparks and Edwards (2010) noted the importance of educators exploring ways to provide education for all, Chartock, $(2010$, p. 23$)$ argued that the following instructional strategies could enhance learning:

- Using materials and curricula that reflect students' backgrounds and their needs and interests.

- Displaying in the classroom images that might be familiar to students.

- Maintaining caring relationships.

- Viewing each child as someone who can teach others by bringing their own stories and experiences to the classroom.

- Providing equal opportunities for all students to fulfill their potential regardless of race, religion, ethnicity, gender, class, and abilities.

- Avoiding stereotypes and helping students to recognize that members of the same group may differ in many ways.

- Encouraging respect for differences.

- Avoiding making assumptions about groups of people and the origins of their cultural characteristics and practices. 
- Helping students identify how they are different and alike in terms of their past and present experiences etc.

\subsection{Teacher Education Programs and Preparation of Culturally Responsive Teachers}

Many scholars have noted that teacher education programs have a responsibility to prepare culturally responsive teachers (Gay, 2002; Nganga \& Kambutu, 2009; Villegas \& Lucas, 2014). Although becoming culturally responsive requires a mastery of cultural diversity, creating space for pre-service teachers to engage critically and meaningfully with social issues is essential. Equally helpful is equipping them with skills essential to building bridges across cultural differences (Teaching Tolerance, n.d). Meanwhile, having a knowledge base relative to teaching for cultural diversity enables educators to create culturally sensitive classrooms (Abt-Perkins and Rosen, 2000). Indeed, Smith (1998) argued that culturally responsive teacher education programs "prepare teachers to be respectfully sensitive to the cultures of their students, to learn about and know the cultures of their students, and to use understandings about how culture influences learning in their day-to-day planning for teaching students" (p. 20). Familiarity with the needs, perceptions, and optimum learning environments for all students influences teachers' selection of instructional resources. The instructional decisions that teachers make on a daily basis can profoundly affect learning of children who come from diverse backgrounds (Muschell \& Roberts, 2011; Perez \& Nordlander, 2004; Villegas \& Lucas, 2014).

Given the fact that the majority of teachers in public schools are still White, and many have had little or no exposure to racial oppression and discrimination, it is critical for teacher education programs to use a curriculum that prepares educators to work for diversity (Chartock, 2010). Addressing this issue, Chartock recommended curricula that help pre-service teachers to:

- Recognize their own frames of reference and the language they use to express issues related to race.

- Confront the subjective nature of the recorded Western history.

- Acknowledge the pervasiveness of racism throughout Western history.

- Identify the educational effects of the prejudice in Western History on historically oppressed groups (p. 18).

While the instructional approaches recommended above have value, it is also essential for all educators to willingly examine their positions as well as take risks by being receptive to multiple perspectives and conversations about inequality and race issues (Chartock, 2010). Additionally, they should recognize that what is normally done in the schools might be very different from what happens at home for children from linguistically and culturally diverse settings.

Dealing with diversity and social justice in the lives of children, their families, and the community is a priority in early childhood education (Nganga, 2015; Ragnarsdottir and Schmidt, 2014). As a result, Ragnarsdottir and Blondal (2014) argued that early childhood educators should incorporate in their programs policies and practices that reflect a broad range of up-to-date diversity issues in order to address the multifaceted issues that children in diverse families and communities experience. However, current research suggests that many obstacles hinder the implementation process of equality-promoting practices (Ragnarsdottir \&Blondal, 2014). It is, therefore, crucial for teacher education programs to prepare pre-service teachers with essential skills relative to implementing effectively diversity related curricula (National Council to Accreditation of Teacher Education (NCATE), 2005; National Association of Multicultural Education (NAME), 2005). In fact, one of NCATEs standards requires the development of "classroom and school climate that values diversity" (p.29). Such a classroom supports learning that has multicultural content. Therefore, a learning climate that natures respect for all, while providing educational equal opportunities is the norm.

\subsection{Use of Culturally Relevant Materials and Instruction in Pre-Service Teachers' Education}

According to Gay (2000), culturally responsive teaching encompasses an assortment of instructional approaches. For example, instruction that is culturally responsive uses culturally relevant materials while embracing cultural sensitivity. In addition, it fosters essential skills in cultural competency. Thus, it ensures that teaching and learning resources are informed by learners' backgrounds in order to limit cultural mismatch between school and home environments. Given the value of culturally responsive education, Rhodes (2013, p. 171) recommended the inclusion of the following instructional approaches:

- Acknowledging the legitimacy of the cultural heritage of different ethnic groups.

- Incorporating multicultural information, resources, and materials in all the subjects and skills routinely taught in schools.

- Using a wide variety of instructional strategies that are connected to different learning styles.

Meanwhile, other studies have found that the use of multicultural literature is helpful in shaping learners' perceptions. 
Consider, for example, Spears-Bunton, (1992); Willis and Johnson (2000) finding that using multicultural literature helps to improve students' self-esteem, involvement and engagement, and academic performance. In these studies, the level of involvement and engagement of African-American students increased when culturally relevant literature and instructions were used. Using multicultural children's literature is a powerful tool to honor students' cultural backgrounds and to foster cross-cultural understanding. Cameron, Rutland, Brown and Douch (2006) also found that children ages 5 to 11 years old who read books that show children of different ethnicities and gender being friends have more favorable views of stigmatized groups; a finding that was clearly supported by Cameron et.al., (2006. P. 1208) in their assertion that children's books that address interethnic friendships could be "a possible prejudice-reduction tool for use with students as young as 5 .

Multicultural literature can also be used to broaden students' understanding of other cultures. In addition, it can help them to develop cross-cultural, intra-cultural and multicultural skills, including gaining an understanding of differences and similarities (Nganga, in- press). Teachers of young children, therefore, should use multicultural literature and talk about human differences and topics that relate to issues of diversity (Derman-Sparks \& Edwards, 2010). However, many teachers have limited experiences using books that are written from "the perspective of or about racial ethnic minorities. As there are numerous issues to consider when choosing multicultural literature, teachers must learn how to assess books as appropriate for use in the classroom" (Wilkins \& Gamble, 1998, p.29). According to Derman-Sparks \& Edwards (2010), while selecting anti-bias culturally responsive children's books, one must use a critical lens, and do a careful evaluation. Equally important is to do an assessment of instructional materials in order to ensure that: a) The used images counter stereotypes- that is, do not always show boys playing outside and girls playing inside, African Americans as athletes while White people work as professional etc., b) The materials used do not just show traditional rituals or historical images of ethnic groups, c) The materials used do not depict misinformation of an ethnic group, and d) The materials used do not exaggerate the features or depict an ethnic group unrealistically (Derman-Sparks \& Edwards, 2010, p. 45). It is, therefore, critical for teacher education programs to provide pre-service teachers with skills and teaching practices that create classroom environments that promote respect in a context of culturally relevant literature.

An education that appreciates all cultures takes many formats. For example, it can be implemented through culturally responsive teaching materials. Such instructional materials and activities should permeate everything that happens in the classroom instead of limiting it to a few lessons. Curricula infusion is especially critical in early childhood programs and schools. Consider, for example, Derman-Sparks (1989) notion that children start to notice differences at an early age as is evident in the fact that they become aware at very young age that "color, language, gender, and physical differences are connected with privilege and power-racism, sexism, and handicappism (p.ix). Multicultural learning opportunities should, therefore, be provided to children starting at an early age. Thus, the use of culturally responsive materials in pre-service programs is crucial in making sure that these future educators acquire knowledge and dispositions that will help them to meet the needs of all learners.

Notwithstanding the importance of using a culturally responsive curriculum, it is usually unpopular because it tends to disrupt existing positions of power and privilege. To that end, Harkins, Ray, and Davis (2010), noted that:

Addressing diversity is often viewed as challenging and discussing the more volatile issues of power and privilege is like walking into a minefield. Understandably, the consequence of revealing the social and historical practices that have created unequal dynamics has led to tension with fellow white colleagues, especially those with even greater privilege. This resistance by privileged individuals, whether white male faculty or students, takes many forms including: denying or challenging information, interrupting/disrupting the conversation, passive participation, changing the subject or claiming reverse discrimination (n.p.)

Educators can overcome some of the resistance experienced through the use of pedagogical approaches that require reflection, exposure to materials that are culturally responsive, and by helping learners to develop better self-awareness especially in the context of social change. In conclusion, however, culturally responsive materials, when used well can provide learners with a positive and accurate learning environment. In early childhood settings, for example, the use of culturally responsive anti-bias curriculum can help children to resist incorrect messages about themselves and others. As a result, it is important for pre-service teachers to acquire skills and knowledge that will help them to become culturally responsive educators. Thus, in this study, the researcher was interested in examining how pre-service teachers perceived an anti-biased culturally responsive curriculum. In addition, the researcher was interested in documenting the effects of culturally responsive anti-bias instructional materials and strategies on pre-service teachers' beliefs and practices about culturally responsive anti-biased education. This study was guided by two theories, namely, Culturally Responsive Teaching (CRT) and the Transformative Learning theory. 


\section{Culturally Responsive Teaching (CRT)}

In culturally responsive teaching, students' are placed at the core of the learning process (Gay, 2002; Gupta, 2014). CRT utilizes "cultural knowledge, prior experiences, frames of reference, and performance styles of ethnically diverse leaners (Gay, 2000, p. 29).

CRT validates and empowers ethnically diverse learners by cultivating their cultural integrity, abilities and academic success (Gay, 2000; 2013; Laughlin \& Nganga, 2009; Nganga, 2015). Banks (2006; 2008) also noted that CRT is an equity pedagogy that aims at eradicating differences between learners' home environments and the school to facilitate success. Additionally, culturally responsive teaching challenges the "master narrative by demonstrating that our world and its history consist of multiple stories and experiences (Banks, 2002). Consequently, an education that is informed by CRT has an emphasis on diversity of knowledge "by rendering unmitigated democratic collaboration between teacher and students as the cornerstone for erudition and discovery" (Cammarota, 2011, p. 63). Equally important in CRT is giving the students a voice in what counts as knowledge, allowing multiple perspectives, fostering divergent thinking, and valuing students ideas (Apple, 2006; Grant\& Sleeter, 2007; Nganga \& Kambutu, 2013;Nieto, 1996).

\subsection{Transformative Learning Theory}

Another theory that informs this study is Transformative Learning (Mezirow, 1991, 2000). According to Mezirow (1991) transformative learning is defined as a process in which learners can change their meaning schemes and meaning perspectives. These meaning schemes have also been referred to as frames of reference that include "both habits of mind and points of view" (Mezirow, 2000, p. 17). According to Mezirow, these schemes and frames of mind stem from the socialization that people receive as children. All human beings are born into social groupings with distinct social identities. The process of learning the identities (cultures, norms, expectations, and values) of the group that a person is born into is called socialization or domestication (Harro, 2000; Nganga, 2012; Ruiz, \& 1997). Socialization influences how people understand their "convictions, habits, ways of acting and altogether the way in which we live our lives" (Illeris, 2014, p. 7). Thus, as individuals interact with family members and the larger community, for example, they internalize the values supported by those entities. Consequently, families and other primary contacts influence the most a child's sense of reality and belonging. Because individuals develop within a socio-cultural context, they are likely to internalize the knowledge, skills and dispositions, including modes and styles of communication, patterns of knowledge, skills, behaviors, attitudes, and beliefs of a given family or community (Owocki and Goodman, 2002; Nganga, 2012; Pia and Adler, 2001).

To facilitate transformation, a transformative approach to teaching is, therefore, essential. Consequently, Taylor (2009) suggested several elements that are key to transformation. These elements are discussed in Illeris (2014, p. 8-9), and they include: 1). Individual experiences that learners bring to the learning environment. The teacher must provide activities that support development of experiences and reflection that can provide learners with new ideas of understanding themselves and their surroundings. 2). Critical reflection- Reflection should focus on content, process (how content is received and elaborated) and underlying conditions for both. Thus, it is not only important to provide situations where learners talk about various issues, but also to encourage them to express themselves in reflective writing. 3). Dialogue- Dialogue with self and others is also a critical component of transformative learning. Dialogue facilitates both the individual and common transformation. According to Illeir, it is through dialogue that critical reflections take place and boundaries of "the individual are discovered, challenged and exceeded" (Ileris, 2014, p. 9). 4). Holistic orientation- An orientation that considers not only the cognitive aspects of reflection but also the emotional and social dimension is also key to transformative learning. These components help learners to overcome resistance to new learning through the creation of a community of learners and empathic connections. 5). Awareness of contextThis element helps in the development of a deeper appreciation and understanding of personal and social cultural aspects involved. For example, learners who have experienced a life-changing event are more receptive to change.

The goal of transformative learning, therefore, is to help learners to critically think about their learning through reflection. To that end, Freire (1970) concluded "an act of learning can be called transformative only if it involves a fundamental questioning and reordering of how one thinks or acts" (p. 139). Furthermore, Merriam (2004) added that for true transformation to take place, it is not the experience in itself that is important. Rather, it is the intellectual growth that follows the process of reflections. Consequently, various aspects of transformation lead to the disassembling of previously held assumptions and misconceptions, including examining them from multiple perspectives (Nganga, in-press). 


\section{Methods}

This study used data from 10 pre-service teachers enrolled in an early childhood course. All participants were elementary and early childhood majors who were seeking an early childhood endorsement. The collection of data occurred over a sixteen-week period, and it consisted of participants' responses to questions, discussion notes and reflections. Discussion questions focused on course work, individual experiences, pre-service teachers' perceptions of their race and culture, and how these identities could affect their work in diverse classroom settings. During the readings, the participants reflected on what they were learning regarding culturally responsive practices, teaching from anti-bias perspective and selecting children's literature for diverse learners. Class discussions were used to help stimulate critical thinking and to relate readings to other course work and assignments. The following questions guided this study:

a. How do pre-service teachers perceive anti-bias culturally responsive teaching?

b. How might using anti-bias culturally responsive materials in course work impact views of pre-service teachers regarding teaching diverse learners?

c. How might self-awareness and self-reflection support transformative learning?

\subsection{Context of the Study}

The study was conducted in the spring of 2014. The participants were enrolled in an early childhood course entitled School Programs for young children at a small teacher education program in a rural state in the Rocky Mountain Region in the U.S. The majority of students in the program were female and White. The state's population is 84.1 percent White, Non-Hispanic (Star Tribune, 2014). This state has one of the lowest percentage of ethnic minorities in the U.S., a situation that is potentially problematic. Reflecting on this reality, Swalwell (2012) noted that "bringing multicultural education into racially uniform classrooms can be a daunting task. Parents and administrators may see no need for attention to inequality. They also may encourage teachers to superficially cover or celebrate "other" cultures in uncritical ways" (p. 24). Consequently, because of where they grew up, the pre-service teachers in this study had little or no exposure to diversity or issues related to social justice. In addition, they typically return to their rural schools when they complete their degrees and are not motivated to teach courses with strands in diversity and social justice (Collin, 1999).

Although the state is generally White, people of color are gradually migrating to different parts of the state (Liu, 2007). According to the Star Tribune (2014) the state's "minority population - defined as any group other than single-race non-Hispanic Whites grew by 17 percent from 2010 to July 2013, accounting for 13,444 people" (n.p). The growth was mostly experienced among Hispanics at 12.2 percent increase from 2010 to 2013. The population of Blacks also doubled while that of Asians and Pacific Islanders and other minorities rose by fifteen percent. As a result, most public schools in the state experienced an influx of children whose first language was other than English, thus creating an additional impetus for this rural education program to prepare teachers who are culturally responsive. With increasing diversity, providing critical multicultural education to pre-service teachers is crucial, as these are the people who will be responsible for preparing young people who have to learn how to live outside of their comfort zones in an increasingly diverse world (Swalwell, 2012).

\subsection{Course Description}

The course helped pre-service teachers to describe, identify, and examine programs and best practices to teaching young children in school settings. Lectures and discussions were supported by a 30- hour practicum experience in an early childhood setting ( 2 hours per week). The course had the following two outcomes:

1. Observing, documenting, and assessing to support young children and families;

2. Teaching and learning (Connecting with children and families; using developmentally effective approaches; understanding content knowledge in early education; building meaningful curriculum).

For the purpose of this study, the researcher focused on the "teaching and learning" outcome and purposefully selected literature that challenged traditional works used in the course. These outcomes were integrated in a variety of assignments and activities in the early childhood course. The pre-service teachers in the course were assigned two common readings- one at the beginning of the semester, that is, Anti-bias education for young children and ourselves by Derman-Sparks and Olson-Edwards (2010), and The girl with the brown crayon the other by Paley's (1998), assigned during the second half of the semester. The researcher hoped that learning about an anti-bias culturally responsive curriculum from the first book would help pre-service teachers to transfer that knowledge to the approach recommended by Paley. In addition, the participants read and assed a children's book of their choosing, based on age 
appropriateness and culturally relevant themes. The researcher developed a rubric to facilitate this process.

\subsection{Data Collection}

Ten pre-service teachers enrolled in an elementary and early childhood education program were subjects in this study. The participants were all females, 90 percent were White and 10 percent Hispanics. Data were gathered during course work for one semester (spring, 2014). Data were in the form of reflections and discussion notes. Because this was a course related project, and it did not pose any harm to participants, the researcher requested the participants to sign a consent form only allowing the collected data to be used for research purpose. The researcher explained to the participants at the beginning of the semester that that their participation was voluntary and would not affect their course grades at all.

The participating pre-service teachers reflected in writing once a week for sixteen weeks regarding course work and their progress. In addition to analyzing these reflections, the researcher took notes during class discussions. To collect additional data, the participants completed open-ended questions before and after course instruction. The purpose of an open-ended questionnaire was to help the researcher to "find out respondents' views in some depth" (Mukherji \& Albon, 2010, p. 135). According to Mukherji and Albon (2010), open-ended questions help to generate rich qualitative data because respondents provide information on their ideas, attitudes and values. This study does not intend to identify causal relationships between previous knowledge and the knowledge gained from pre-service teachers' experiences in this course. Rather, it is aimed at exploring the perceptions of pre-service teachers to a culturally responsive anti-bias early childhood curriculum and how implementing such a curriculum in course work might influence those perceptions.

\subsection{Data Analysis}

Data were analyzed using qualitative approaches (Mukherji and Albon, 2010; Nolan, Macfarlane, \& Cartmel, 2013). The researcher looked for patterns in the information gathered to generate themes. This data analysis approach helped in the coding process. Data with similar responses were placed in the same category. To determine validity and reliability of responses in open-ended questions and reflections, the researcher took notes during class discussions and compared it to the information previously provided. This checking helped the researcher to gain a deeper understanding of the data. Pseudonyms were used to ensure pre-service teachers' confidentiality.

\section{Results}

Four themes emerged from this study. These were;

1. Pre-service teachers' misconceptions about a culturally responsive anti-bias curriculum.

2. The need to engage culturally responsive anti-bias materials in pre-service teacher education.

3. The importance of analyzing children's books for cultural relevance and anti-bias.

4. Importance of self-awareness and self-reflection in teaching to diversity.

\subsection{Pre-service Teachers' Misconception about a Culturally Responsive Anti-Bias Curriculum.}

Perhaps the most revealing finding in pre-teaching data were the responses to the question; What comes to mind when you think about anti-biased classrooms? Pre-assessment data revealed many misconceptions as well as lack of depth in understanding of anti-bias curricula. For example, several pre-service teachers indicated that a culturally responsive anti-bias classroom is where:

- There is learning about different cultures and how to teach it (Pora).

- There are items from different countries (Dona).

- The students cook a foreign dish and wear indigenous people's clothes to celebrate a cultural holiday (Jena).

Others students reported that watching videos with exotic dances and using such video as teaching resources during certain holidays would be helpful. While the above responses are applicable to cultural studies, they reflect a superficial curriculum that lacks depth (Derman-Sparks \& Olson-Edwards, 2010; Banks, 2001). Meanwhile, responses to the second question (In your opinion what teacher practices make a classroom anti-biased? Why do you think these practices are culturally responsive and anti-biased?) reviewed additional misunderstanding as is evident in the following responses:

Not being biased is when a teacher pulls random note cards with students' names during discussions (Mina). 
A teacher could have students draw themselves and they could hang the art work on the classroom wall. Knowing a child's background (Stacey).

Although the use of random note cards helps a teacher to distribute questions and also promotes students' participation, Mina fails to explain why it is an anti-biased practice. Nonetheless, encouraging participations of both boys and girls promotes gender equity (Derman-Sparks \& Olson-Edwards, 2010). In Stacey's response, she recognizes the importance of displaying students' work in the classroom. However, she too, does not make any connections to an anti-bias culturally responsive education. Additionally, although knowing a student's background is important, being able to use that information to meet the needs of diverse learners would be helpful. According to Derman-Sparks \& Olson-Edwards (2010), anti-bias educators design their work based on the cultural backgrounds of the children and families in their program.

Other pre-service teachers provided similar basic details of a culturally responsive anti-biased practice. For example, Jena indicated that such a curricula "invites a guest from another culture such as Mexican or Asian to present in the classroom."

All the data that the researcher collected during pre-teaching showed that the participating pre-service teachers' responses reflected misconceptions about anti-bias curriculum. For example, in Jena response, that mirrors a majority of the participant's responses, a perception that seemed to equate having a guest speaker as an anti-biased practice is evident. According to Derman-Sparks (1989) this teaching approach has a "tourist focus" because it treats other cultures as exotic. Banks (2001) also noted that in such a curriculum, students learn little or nothing about a given ethnic group before or after the special event or occasion being celebrated. Additionally, according to Brown University (2008), a focus on easily stereotyped artifacts from a culture such as food or clothing does not reflect cultural sensitivity. An ideal practice would be using instructional materials and teaching themes that are of interest to the students. "Anti-bias education is not just a set of activities for occasional use (although that is often how new anti-bias educators begin). It is a focus that permeates everything that happens in our program" (Derman-Sparks \& Olson-Edwards, 2010, p. 8).

In contrast to pre-teaching data, post-teaching responses revealed that pre-service teachers had a better understating of a culturally responsive anti-biased curriculum. Their reflections, for example, showed depth because they realized that teachers needed to broaden their understanding of themselves as well as the challenges of implementing an anti-biased curriculum. To that end, Dona contended:

At the beginning of the semester, I was not sure what an anti-biased culturally responsive curriculum was. I thought having students listen to music from another culture was culturally responsive in itself. I now know that listening to music is not enough. As a teacher, I also need to have a discussion with students about cultural differences and similarities. Teachers who are committed to a culturally responsive anti-bias curriculum uphold the principle that every child deserves to develop to his or her fullest potential (Dona).

In another post-teaching response, Mina who initially thought that a culturally responsive anti-bias curriculum was about calling students names randomly held a different perspective at the end of the semester as is evident in the following response:

Although making sure one calls on all students for sharing is important, a teacher also needs to establish a relationship of care and an environment where all students can learn no matter what their culture is. It is also important to have gender free activities and avoid stereotypical roles for boys and girls.

Evidently, Mina's response shows a better understanding of culturally responsive education especially because she now identifies the establishment of positive relationships, as well as the need to create safe learning environments as key ingredients. Meanwhile, other participants showed a similar growth, and they were able to express why it was important to include activities that promote positive social identifies such as those that "avoid stereotypical roles for boys and girls," thus allowing children to explore and form positive social identifies. In addition, many of the pre-service teachers in this study began to recognize and appreciate different viewpoints. Consequently, one pre-service teacher reported that:

I need to listen to others without making them feel like their stories are not valid. Growing up privileged (White and middle class), I always questioned perspectives of those who are different. I considered my experiences to be the norm and therefore anything that was contrary to my mindset, I viewed it as wrong or not authentic (Winne).

In conclusion, at the beginning of the semester, the pre-service teachers in this study seemed to have difficulties identifying a culturally responsive anti-bias curriculum. They also lacked depth in their responses about how such a 
curriculum should look like. However, at the end of the semester, their responses showed a better understanding. Equally important was that they recognized the importance of assessing materials for bias, and using multiple methods of instruction to meet the needs of diverse learners.

\subsection{The Need to Engage Culturally Responsive Curriculum Materials in Pre-Service Teacher Education}

Data from this study showed that class discussions, assigned readings and course content helped the participants to develop a deeper understanding of a culturally responsive curriculum, as well as considerations that they need to make for such a curriculum to become a reality. While pre-teaching data showed that Jena thought that a culturally responsive anti-bias curriculum involved making of foreign foods in one's class and celebrating holidays, at the end of the semester, she had a different perspective as is evident in the following response:

I found course work very helpful. Although I thought celebrating holidays in my class could be fun, I learned that they could also cause problems. I learned that holidays are not universal. I also learned that some people prefer not to celebrate certain holidays due to their beliefs and others see holidays as a commercialized attempt for businesses to make money. I have never thought of holidays in this way. I always looked at the fun part of it. No wonder we have so many advertisements to go buy stuff.

In the above feedback, Jena shows a possible development of a new perspective. In addition, she appears to question what she believed as the "norm". Evidently, the assigned classroom dialogues, readings and assignments helped Jenna to construct new knowledge. Because holidays are not universal, Jena and other pre-service teachers were able to identify how using a holiday curriculum could be problematic. At the same time, however, the participants in this study were able to come up with a solution that might work for their students- see excerpt below:

Before using a holiday curriculum in my classroom, I will need to do a survey to get to know my students and their families and what cultural practices are important to them. I also need to find out what holidays, if any, my students might celebrate. Additionally, I have to always have other activities ready for those who might not celebrate a holiday (Dona).

In the above response, Dona, like Jenna, seem to understand that while incorporating holidays in the curriculum can help children learn about other cultures, such an inclusion has shortcomings that should be addressed. For example, Dona cites the making of food from one culture as a "tourist approach" since it is a one-day event that lacks depth of the study of a culture. Equally impressive was the realization by other pre-service teachers that families have different values, and that working with families to determine inclusion of a holiday curriculum or not to, is important. Involving parents of culturally diverse students is key to the success of a culturally responsive curriculum because parents interact with their children before schoolteachers get the opportunity to do so. Consequently, parental suggestions can help the teacher to know how she/he could help his/her students to succeed. Another finding delved into the importance of analyzing children's books for cultural relevance.

\subsection{The Importance of Analyzing Children's Books for Cultural Relevance and Anti-Bias}

Although some pre-service teachers had difficulties analyzing children's books for cultural responsiveness and biases, post-teaching data showed that the participants developed essential pertinent skills. Consider, for example, the following pre-teaching response from a student who struggled to respond to the question: "Why is the book you selected appropriate to teach anti-bias and social justice education?"

The book I selected was What We Wear: Dressing Up Around the World" (Ajmera, Derstine \& Pon, 2012). This book is appropriate because it shows different clothing from all around the world. The children would learn to be open-minded by looking at pictures (Tamera, 2014).

In this response, a deeper analysis is lacking. An appropriate response, therefore, should address issues of customs, similarities, difference, and why people wear different clothes. Equally important would be to explain in what ways the book might help children to become open-minded. Other responses, though, showed a deeper understanding and analysis. For example, most of the participants reported that it is important for educators to be aware of the content and pictures in children's books, and be aware of the messages conveyed, both intended or unintended. This was evident in many responses where the participating pre-service teachers expressed the need to carefully select books that do not reinforce existing stereotypes. Additionally, the participants stated that teachers must select children's books that show respect of differences, empathy and care, as well as feature-underrepresented groups in positive roles as is evident in the following response by Lucy:

I choose "The Skin You Live In" (Tyler, 2005). This book is appropriate to use for teaching anti-bias and culturally responsive lessons because it uses colorful pictures and developmentally appropriate vocabulary to 
describe concepts. In addition, it focuses on the fact that everybody is different, but we are all valuable. It teaches children that the skin color doesn't matter as much as the person inside. The concepts are addressed in a socially just way because everybody is valued and represented. I also liked this book because I could see myself using it to teach about diversity to young learners because the author represents a variety of social groups, and equal attention is given.

Reflections from pre-service teachers also suggest that analyzing children's books helped them to open up to other ways of seeing, thinking, and teaching. Elaborating this point, two pre-service teachers responded thusly:

Analyzing children's books was one of the assignments that I really liked. Through this activity, I was able to reflect on why it was important to make sure the materials I choose do not stereotype certain groups. Seeing my peers talk about why they selected their books also helped me to think about things that I did not think about before taking this course (Jena).

As a teacher, it is important to consider my biases while selecting materials. The assignment to evaluate a children's book was really a revelation. I have never considered evaluating children's books. Analyzing and discussing children's stories for unfairness and fairness can help children learn how to recognize such acts in real life and what to do about them. As a teacher, I therefore should take time to evaluate such materials for stereotypes as well as select materials that children can identify with (Lucy).

These comments suggest that engaging in an activity that analyzes reading materials could open space to reflect. Reflection in this case can be a beginning of shifting paradigms; an essential component in the process of transformation to an anti-biased culturally responsive educator.

\subsection{The Importance of Self-Awareness and Self-Reflection in Teaching to Diversity}

Data from this study revealed that self-awareness and reflection are important while teaching to diversity issues. To that end, many of the participating pre-service teachers acknowledged that the opportunity to think about their own identities was helpful. Consequently, these participants seemed to realize that their own biases were rooted in their experiences and socialization. This realization was important in helping them to challenge stereotypes and status quo. To that end, Pora wrote the following about her internalized privilege:

The readings and class discussions made me begin to realize that I have been "spoiled" because of my father's money while I was growing up. I have not known any other life other than my own, which is sad. To me, it was normal to live a life of plenty. I thought every child had the same live. I did not even know being White, I was privileged. Looking back, I see things I took for granted and realize I did not have to think about them because of my skin color and race. I feel that when I teach, it is important to introduce students to many ways of life so that they can see what both oppressed and privileged people live like. It is also important to discuss why some people are privileged, why others are not, and how we can make it better for all. By unraveling my own privileges and oppressions, I can become a better teacher. I know I have a long way to go. But this has really helped me (Pora).

In the above reflection, Pora appeared to gain new insights regarding her social identity. Notwithstanding her upbringing and place in society, for example, with her new learning, Pora realized that she could make a difference in children's lives. This new learning is congruent with Kozleski (n.d) thinking that becoming culturally responsive calls for teachers and students to learn to negotiate new ways of doing things as well as acknowledging differences and similarities that exist between different ethnicities and groups. Additionally, Pora's response showed a willingness to respect diversity and an acknowledgement that there are many worldviews. To that end, the teacher's view is, therefore, not the only one that is valid. Such an understanding is critical in the change process. In Pora's case, the desire to become an anti-biased educator is the beginning of the journey.

Another revelation from the generated data shows that pre-service teachers were able to analyze published works based on their new learning. For example, while discussing Paley (1998) book, The girl with a brown crayon, a majority of the pre-service teachers in this study were able to not only identify qualities that made Vivian Paley a culturally responsive anti-biased teacher, but they also made connections to course content regarding selection of anti-biased children's books. Additionally, they identified how they could apply the knowledge gained in their own classrooms as is evident in response below:

Vivian deals with issues that teachers sometimes do not want to cover. Others do not want to trend on issues such as gender, race, oppression and identity. As a future teacher, I will use books that represent different cultures like the teacher in this book did to push my students and to broaden their thinking and understanding. I really liked how Vivian used children's books to teach about cultural diversity to her students (Anna). 
In the above response, Anna realized that becoming a culturally responsive and anti-biased educator required one to provide a learning environment where all children benefited, where class materials represents diverse leaners, and where topics that are sometimes deemed difficult are included. Another important takeaway for pre-service teachers was that as teachers, they had the power to change students' lives in positive ways. As earlier noted, growing up in predominantly rural White communities, the pre-service teachers in this study had little or no experience with diversity. Additionally, they grew up with the notion that everyone can "pull themselves up by their bootstraps." However, by the end of the semester, their previously held views appeared to change. Instead, the participating pre-service educators appeared to realize that some students needed help getting "boots and straps." This realization was further expressed in Dona's self-reflection provide below:

One of the most important things I learned was that as a teacher, I have the power to make or break a child and give him/her a great headstart or pull them back. The saying "pull yourself by your bootstraps" can only work, if one has a "boot." Although some students have a good foundation or a boot, others do not. Life at home is also very different. Some students have support and economic resources (boots and straps), others come from supportive poor families and might have a boot but no straps. Some people are also oppressed by existing systems.

In conclusion, it is clear from the response provided that the participating pre-service teachers experienced learning that influenced their development as culturally responsive anti-bias educators. As a result, it is fair to argue that integrating culturally responsive anti-bias materials into the existing course is essential. Perhaps because of the planned instructional and learning activities, the participants in this study reported that they were more aware of the impact of cultural diversity in the classroom. So, for pre-service teachers to learn what it truly means to be anti-biased educators, it is essential to expose them to content that challenges their pre-existing notions.

\section{Discussion}

Because teacher education programs play an important role in helping pre-service teachers develop skills and competencies essential to working effectively with diverse learners, infusing a culturally responsive pedagogy throughout course work can provide a strong foundation (Nagda, Kim, \& Truelove, 2004; Nganga \& Kambutu, 2009; Villegas, 2002). To that end, data from this study showed that infusion of a culturally responsive anti-biased curriculum seemed to influence how pre-service teachers interpreted the meaning of becoming culturally responsive anti-biased educators.

Although pre-teaching data showed that the participants held misconceptions about the meaning of a culturally responsive anti-biased curriculum, by the end of the semester, they seemed to have developed a better understanding of what such a curriculum looked like. Additionally, they gained a new way of examining and interpreting practices, which had previously seemed normal. This result mimics Ladson-Billings (1995) finding that in order for pre-service teachers to teach in culturally relevant ways, they need support and opportunities to practice such a curriculum. Additionally, Mensah (2011) and Martin, Smolen, Oswald and Milam (2012) noted that activities that promote empowerment, and personal relevance of the subject matter are important practices for teacher educators to adopt in the preparation of teachers for diverse learners.

In this study, however, pre-service teachers began to question their previous assumptions. Because humans are products of their heritage, they get used to doing things the way they saw those in their communities and families do them. Thus, the pre-service teachers in this study who are overwhelming White and middle class tended to use their "norms" as a model for what culturally responsive anti-biased education should look like. However, after being exposed to culturally responsive anti-bias course work, these participants became more literate about what it means to be anti-biased teachers as thy evaluated course materials, teaching practices, and reflected on their own learning.

Another finding from this study was that analyzing children's books allowed the participants to develop skills for assessing materials for culturally responsiveness and anti-biasness. This result indicates that pre-service teachers rely on teacher educators to model the desired pedagogical and instructional practices. Consider, for example Morgan (2009) view that culturally authentic children's books have been used for many years to help learners feel appreciated and for the development of positive cross-cultural attitudes. Additionally, these books can help eliminate misconceptions and misunderstanding between underrepresented groups and the mainstream culture. Nonetheless, not all books represent culturally diverse groups in authentic non-stereotypical ways. Thus, providing pre-service teachers with knowledge and skills to self-critique and to evaluate materials is key in developing of multiple perspectives. Equally important was the self-realization that their socialization and race mattered in how the pre-service teachers in this study worked with those from diverse groups. As such, consulting with parents and students on issues important to 
them, along with inclusion of materials and activities of interest was important to diverse learners. Meanwhile, Gay (1994) argued that a "deeply ingrained cultural socialization becomes problematic in education when the schooling process operates on one cultural model to the exclusion of all others, or when culturally different children are expected to set aside all their cultural habits as a condition of succeeding in school" (p. 5). Thus, providing opportunities for pre-service teachers to explore their own identities and socialization through course work can be helpful. To that end, Derman-Sparks and Edwards (2010) reported that racial identity is about how we are treated by society and how we feel and live our racial group membership. Indeed, children are impacted by how their race is perceived by societal institutions.

Through reflection, the participants in this study had the opportunity to think about their own racial identity, and what that meant while working with children in a society that is highly racialized. Equally important, was the development of a better understanding of themselves as White, middle class and privileged people. By doing so, they had room to explore their privileges, and ways in which they could create change in their classrooms. According to Harkins, Ray and Davis (2010) the classroom can be used as a vehicle to bring about long-term systemic social change through transformational teaching approaches. That is because classrooms provide an ideal forum to engage in dialogue with students for a lengthy period. Thus, by using teaching materials and instructional practices that encourage self-reflection, the pre-service teachers in this study were more willing to engage information that was at times challenging since it did not align with their socialization and privileged positions. Subsequently, they realized that without equal opportunities, educators could not expect all children to learn. As such, culturally responsive anti-biased teachers recognize these aspects of inequalities and their impact to learning. Furthermore, Fennimore (2008) stated that "every educator of children must continually reflect upon, honesty recognize, and seek to change bias that may have assimilated into personal belief systems during childhood and adolescence" (p. 194).

Like other researchers, this study found that it is possible that pre-service teachers take steps, each in his/her own way to move towards becoming a better educator (Atwater, et al., 2010; Derman-Sparks and Edwards, 2010). Consequently, recognizing personal bias and seeking change is a lifelong journey for teachers who are committed to social justice. Then, it appears that it is crucial for teacher educators to model culturally responsive anti-biased practices to their pre-service teachers (Chartock, 2010). Accordingly, pre-service teachers need sufficient opportunities to reflect, assess materials, and plan activities that help them to apply culturally responsive teaching (Mensah, 2011). Thus, Mensah stated that:

As teacher educators, we serve as supporters and advocates for our pre-service teachers' on-going professional development. In addition, we need thoughtful, well-planned teacher education curricula and activities that educate our pre-service teachers in learning what CRT (culturally responsive teaching) is, and its potential usefulness to not only in their classrooms but also for their education (p. 308).

In all, then, this study shows the relevance and application of a culturally responsive anti-bias curriculum in teacher education courses.

\section{Recommendations and Implications for Teacher Education Programs}

The findings from this qualitative study have implications for teacher education programs and furfure research. First, data suggested that pre-service teachers could struggle with their ideas of what makes a curriculum culturally responsive and anti-biased. Second, infusion of a culturally responsive curriculum in pre-service teacher education courses could provide future teachers with opportunities to develop the knowledge and skills they need to teach culturally responsive curricula. As is evident in this study's responses, when issues of race and privilege are not addressed, educators are likely to develop and/or maintain pre-conceived notions that race does not matter or has no impact on students' learning. Such notions could lead to false claims that there are no barriers to success, and failure is not a consequence of social structures, but of an individual's lack of initiative (DiAngelo, 2010; DiAngelo \& Allen, 2006). As a result, pre-service teachers who are overwhelmingly White and middle class might not recognize how race and social economic status might affect learners from diverse backgrounds. To that end, Terry and Irving (2010) noted that attitudes related to power, privilege and status may make it difficult for some educators to value diversity among their students. Thus, it is critical for teacher educators to help pre-service teachers who are overwhelming White to understand the different factors that influences the success of diverse learners. Indeed, "critics from both inside and outside teacher education have suggested that traditional.... teacher education has not done an adequate job preparing teachers to teacher diverse populations (Hollins \& Guzman, 2005, p. 478). As a result, Scott, Alexander, Fritton and Thoma reckons \& Graff (2010, p. 88) recommended that all teacher education programs to help pre-service teachers examine "their complexities, attitudes, and behaviors towards issues of diversity." 
Teaching for diversity requires the implementations of various instructional models. Nevertheless, an ongoing examination of curriculum materials is essential. Because the U.S. is a highly racialized society, and because the education system mainly follows the norms of the dominant groups, it is critical for teacher education programs to equip pre-service teachers with essential culturally relevant skills. Indeed, data from this study showed that when given the opportunity to reflect upon their notions of culturally responsive anti-biased practices, examining materials and engaging in self-reflections, pre-service teachers are capable of developing knowledge, skills and dispositions that are consistent with the practices of culturally responsive anti-biased education. It is this researcher's belief that teacher educators have a key responsibility to infuse a culturally responsive anti-biased curriculum into their teacher education courses.

\section{Conclusion and Limitations}

Findings from this study are limited to one course. Notwithstanding, however, these findings suggest that although the participating pre-service teachers had misconceptions regarding a culturally responsive anti-bias curriculum before experiencing instruction, they developed a better understanding and appreciation after experiencing different pertinent culturally responsive anti-biased instructional strategies. Additionally, through exposure to culturally anti-biased materials, the participating pre-service teachers developed a desire to promote social justice for children in their daily practices. As a result, the researcher concluded that when equipped with the necessary knowledge and skills, it is probable that all pre-service teachers can become culturally responsive educators.

Support: This work was supported by the Social Justice Research Center (SJRC) at the University of Wyoming.

\section{References}

Abt-Perkins, D., \& Rosen, L. (2000). Preparing English teachers to teach diverse student populations: Beliefs, challenges, proposals for change. English Education, 32(4), 251-266.

Ajmera, M., Derstine, E.H., \& Pon, C. (2012). What we wear: Dressing up around the world. Watertown, M.A; Charlesbridge.

Apple, M.W. (2006). Educating the right way: markets, Standards, God, and inequality (2nd Ed.). London: Routledge.

Atwater, M.M., Freeman, T.B., Butler, M.B., \& Draper-Morris. (2010). A case study of science teacher candidates' understandings and actions related to culturally responsive teaching of 'other' students. International Journal of Environmental \& Environmental Science Education, 5(3), 287-318.

Banks, J. A. (2006). Diversity in American education: Foundations, curriculum and teaching. Boston, MA: Allyn \& Bacon.

Banks, J. A. (2008). Teaching strategies for ethnic studies. Boston, MA: Allyn \& Bacon.

Banks, J.A. (2001). Cultural diversity and education: Foundations, curriculum, and teaching ( $4^{\text {th }}$ ed.). Boston: Allyn \& Bacon.

Bronfenbrenner, U. (1979). The Ecology of Human Development: Experiments by Nature and Design. Cambridge, MA: Harvard University Press.

Brown University (2008). Culturally responsive teaching. Retrieved from http://www.brown.edu/academics/educationalliance/sites/brown.edu.academics.education-alliance/files/uploads/ KLOOM_crt_entire.pdf

Cameron, L., Rutland, A., Brown, R.J., \& Douch, R. (2006). Changing children's intergroup attitudes towards refugees. Testing different models of extended contact. Child Development, 77(5), 1208-1219. http://dx.doi.org/10.1111/j.1467-8624.2006.00929.x

Cammarota, J. (2013). The value of multicultural and critical pedagogy: Learning through diversity and dissent. Multicultural Perspectives, 13(2), 62-69. http://dx.doi.org/10.1080/15210960.2011.571546

Causey, V.E., Thomas, C.D., \& Armento, B.J. (2000). Cultural diversity is basically a foreign term to me: The challenges of diversity for preservice teacher education. Teaching and Teacher Education, 16, 33-45. http://dx.doi.org/10.1016/S0742-051X(99)00039-6

Chartock, R.K. (2010). Strategies and lessons for culturally responsive teaching: A primer for $k-12$ teachers. New York, Pearson. 
Collins, T. (1999, December). Attracting and Retaining Teachers in Rural Areas. EDO RC-99-7.

Darling-Hammond, L. (2002). Educating a profession for equitable practice. In L. Darling-Hammond, J. French., \& S. P. Garcia-Lopez (Eds.), Learning to teach for social justice (pp. 201-212). New York: Teachers College Press.

Derman-Sparks, L., \& A.B.C. Task Force. (1989). Anti-bias curriculum: Tools for empowering young children. Washington, DC: National Association for the Education of Young Children.

Derman-Sparks, L., \& Olson-Edwards J.O. (2010). Anti-bias education for young children and ourselves. Washington DC. National Association for the Education for Young Children.

Deruy, E. (2013). Student diversity is up but teachers are mostly White. American Association of Colleges for Teacher Education (AACTE). Retrieved from https://aacte.org/news-room/aacte-in-the-news/347-student-diversity-is-up-but-teachers-are-mostly-white

DiAngelo R. (2010). "Why can't we all just be individuals?" Countering the discourse of individualism in anti-racist education. Interactions: UCLA Journal of Education and Information Studies, 6(1), Article 4. https://escholarship.org/uc/item/5fm4h8wm

DiAngelo R., \& Allen, D. (2006). "My feelings are not about you": personal experience as a move of Whiteness. Interactions: UCLA Journal of Education and Information Studies, 2(2), Article 2. https://escholarship.org/uc/item/6dk67960

Fennimore, B. (2008). Talk about children: developing a living curriculum of advocacy and social justice. In Genishi, C. and Goodwin, A.L. (Eds.), Diversities in early childhood education rethinking and doing. New York, Routledge. Pp185-189.

Freire, P. (1970). Pedagogy of the oppressed. New York: Seabury.

Gay, G. (2000). Culturally responsive teaching: Theory, Research, practice and research. New York: Teacher College Press.

Gay, G. (2002). Preparing for culturally responsive teaching. Journal of Teacher Education, 53(2), 106-116. http://dx.doi.org/10.1177/0022487102053002003

Gay, G. (2013). Teaching To and Through Cultural Diversity. The Ontario Institute for Studies in Education of the University of Toronto Curriculum Inquiry, 43(1), 48-70. http://dx.doi.org/10.1111/curi.12002

Gollnick D. M., \& Chinn, P. C. (2004). Multicultural education in a plural society. (6th Ed.). New Jersey and Columbus, Ohio: Pearson Merrill Prentice Hall.

Grant, C.A., \& Sleeter, C.E. (2007). Doing multicultural education for achievement and equity. New York: Routledge.

Gupta, A. (2014). Diverse early childhood education policies and practices. New York: Routledge.

Harkins, D.A., Ray, S., \& Davis, T.M. (2010). Diversity consulting and teaching from a social justice perspective. Tamara Journal of Critical Organization Inquiry, 8(4), 135-156.

Harro, B. (2000). The cycle of socialization. In M. Adams, J. W. Blumenfeld, R. Castañeda, W.H., Hackman, L. M. Peters, and X. Zuniga (Eds.), Reading for diversity and social justice (pp. 15-21). New York, NY: Routledge.

Hollins, E. R., \& Guzman, M. T. (2005). Research on preparing teachers for diverse populations. In M. Cochran-Smith \& K. M. Zeichner (Eds.), Studying teacher education: The report of the AERA panel on research and teacher education (pp. 477-548). Mahwah, NJ: Lawrence Erlbaum Associates.

Illerris, K. (2014). Transformative Learning and identity. New York, Routledge. http://dx.doi.org/10.1177/1541344614548423

Kozleski, E.B. (n.d). Culturally responsive teaching matters. Retrieved from http://www.equityallianceatasu.org/sites/default/files/Website_files/CulturallyResponsiveTeaching-Matters.pdf

Ladson-Billings, G. (1995). Culturally relevant teaching. Theory into Practice, 34(3). http://dx.doi.org/10.1080/00405849509543673

Laughlin, P., \& Nganga, L. (2009). Interdisciplinary ways of knowing: A collaborative teacher education project for culturally responsive pedagogy in rural White America. Spaces for Differences: An Interdisciplinary Journal, 1(2), 96-125.

Lenski, S.D., Crumpler, C.T., \& Crawford, K.M. (2005). Beyond awareness: Preparing culturally responsive preservice teachers. Teacher Education Quarterly, 32(2), 85-100. 
Liu, W. (2007). The changing faces of Wyoming Population. State Department of Administration and information economic analysis division, Cheyenne, Wyoming.

Martin, L.A., Smolen, L.A, Oswald, R.A., \& Milam, J. (2012). Preparing Students for Global Citizenship in the Twenty-First Century: Integrating Social Justice through Global Literature. The Social Studies, 103(4), 158-164. http://dx.doi.org/10.1080/00377996.2011.601358

Mensah, F.M. (2011). A case for culturally relevant teaching in science education and lessons learned for teacher education. The Journal of Negro Education, 80(3), 296-309.

Merriam, S. (2004). The changing landscape of adult learning theory. In J. Comings, B. Garner., \& C. Smith (Eds.), Review of adult learning and literacy: Connecting research, policy, and practice (pp. 199- 220). Mahwah, NJ: Lawrence Erlbaum Associates.

Mezirow, J. (1991). Transformative dimensions of adult learning. San Francisco, CA: Jossey Bass.

Mezirow, J. (2000). Learning to thin like an adult: Core concept of transformation theory. In Mezirow, J. and Associates (eds.), Learning as transformation: critical perspectives on a theory in progress. San Francisco, CA: Jossey-Bass.

Milner, H. R. (2003). Teacher reflection and race in cultural contexts: History, meanings, and methods in teaching. Theory into Practice, 42(3), 173-180. http://dx.doi.org/10.1207/s15430421tip4203_2

Morgan, H. (2009). Gender, racial, and ethnic misrepresentation in children's books: A comparative look. Childhood Education, 83, 187-191.

Mukherji, P., \& Albon, D. (2010). Research methods in early childhood. An introductory guide. Sage, CA: Los Angeles.

Muschell, L.H., \& Roberts, H. M. (2011). Bringing the culture gap: One teacher education program's response to preparing culturally responsive teachers. Childhood Education, 87(5), 337-340. http://dx.doi.org/10.1080/00094056.2011.10523209

Nagda, B. A., Kim, C. W., \& Truelove, Y. (2004). Learning about difference, learning with others, learning to transgress. Journal of Social Issues, 60(1), 195-214. http://dx.doi.org/10.1111/j.0022-4537.2004.00106.x

National Association for Multicultural Education (2005). NAME Conference Catalogue, pp. 9-10.Washington, DC.

National Council for Accreditation of Teacher Education (2005). Professional Standards for the Accreditation of Teacher of Teacher Education. Washington, D.C.

Nganga, L. (2012). Children and socialization across two nations (Kenya and U.S.). In Omiunota N. Ukpokodu and Peter Ukpokodu (Eds.), Voices From the Margin: Perspectives of African-Born Teacher Educators on African and American Education(pp. 109-126). Charlotte, NC, Information Age Publishing.

Nganga, L. (2015). Multicultural Curriculum in Rural Early Childhood Programs. Journal of Praxis in Multicultural Education, 9(1), Article 2. http://dx.doi.org/10.9741/2161-2978.1073

Nganga, L. (In press). Global and social justice in teacher education: Using children's literature, threaded discussions and other strategies. In Nganga, L., \& Kambutu, J. (Eds.). Social justice, globalization and teacher education. Charlotte, NC: Information Age Publishing.

Nganga, L., \& Kambutu, J. (2009). Teaching for democracy and social justice in rural settings: Challenges and pedagogical opportunities. In Groenke, S.L.., \& Hatch, J.A., Critical pedagogy and teacher education in the neoliberal era, (119-204). Montreal, Canada, Springer. http://dx.doi.org/10.1007/978-1-4020-9588-7_13

Nganga, L., \& Kambutu, J. (2013). Michael Apple: A Modern Day Critical Pedagogue. In Kirylo, J. (Ed.), A critical pedagogy of resistance. 34 pedagogues we need to know (pp.1-3). Rotterdam, The Netherlands; Senses Publishers. http://dx.doi.org/10.1007/978-94-6209-374-4_1

Nieto, S. (1996). Affirming diversity: The sociopolitical context of multicultural education. New York: Longman.

Nieto, S. (2004). Affirming diversity: The sociopolitical context of multicultural education (4 ${ }^{\text {th }}$ ed.). Boston: Allyn \& Bacon.

Nolan A., Macfarlane, K., \& Cartmel, J. (2013). Research in early childhood. Washington DC, Sage.

Owocki, G., \& Goodman, Y.M. (2002). Kidwatching: Documenting Children's Literacy Development. Heinemann, U.S.A.

Pai, Y., \& Adler, S.A. (2001). Cultural foundations of education ( ${ }^{\text {rd }}$ ed.). Upper Saddle River, NJ: Merrill Prentice 
Hall.

Paley, V.G. (1998). The girl with the brown crayon. MA: Harvard University Press.

Par, T. (2001). It's okay to be different. New York, NY. Little Brown and Company.

Perez, B., \& Nordlander, A. (2004). Making decisions about literacy instructional practices. In B. Perez (Ed.), Sociocultural context of language and literacy (pp. 277- 308). Mahwah, New Jersey, Lawrence Erlbaum associates, publishers.

Pohan, C. A., \& Adam, A. (2007). Increasing family involvement and cultural understanding through university partnership. Action in Teacher Education, 29(1), 42-50. http://dx.doi.org/10.1080/01626620.2007.10463438

Ragnarsdottir, H., \& Blondal, H. (2014). Inclusive practices: Participation and empowerment in a preschool in Iceland. In Ragnarsdottir, H. and Schmidt, C. (eds.), Learning spaces for social justice: International perspectives on exemplary practices from preschool to secondary school. London, Institute of Education Press. pp.9-25.

Ragnarsdottir, H., \& Schmidt, C. (eds.) (2014). Learning spaces for social justice: International perspectives on exemplary practices from preschool to secondary school. London, Institute of Education Press.

Rhodes, C.M. (2013). Culturally Responsive Teaching Practices of Adult Education English for Speakers of Other Languages and English for Academic Purposes Teachers. Graduate Theses and Dissertations. Retrieved from http://scholarcommons.usf.edu/etd/4568

Ruiz, D. M. (1997). The four agreements: A practical guide to personal freedom. San Rafael, California: Amber-Allen.

Scott, L.A., Alexander, Q., Fritton, S., \& Thoma, C. (2014). An Evaluation of Culturally Responsive Practices in Special Education Program for Preservice Educators. Journal of Curriculum and Teaching, 3(2), 79-93. http://dx.doi.org/10.5430/jct.v3n2p79

Sleeter, C.E., \& Grant, C.A. (1994). Making choices for multicultural education: Five approaches to race, class, and gender ( $2^{\text {nd }}$ ed. $)$. New York: Macmillan.

Smith, G. P. (1998). Common sense about common knowledge: The knowledge bases for diversity. Washington, DC: American Association of Colleges for Teacher Education.

Spears-Bunton, L. (2000). Calypso, jazz, reggae, salsa: Literature, response, and the African diaspora. In N. Karolides (Ed.), Readers response in secondary and college classrooms (2nd ed.). Mahwah, NJ: Lawrence Erlbaum Associates.

Star Tribune (June, 2014). Census shows more ethnic diversity in Wyoming. Retrieved from http://rrib.com/news/state-and-regional/census-shows-more-ethnic-diversity-in-wyoming/article_e82e920a-2ca0 $-5 \mathrm{~b} 4 \mathrm{~d}-860 \mathrm{c}-01 \mathrm{abaf} 3 \mathrm{e} 6 \mathrm{c} 51 . \mathrm{html}$

Swalwell, K. (2012). Confronting white privilege. Teaching Tolerance, Fall, 23-26.

Taylor, E.W. (2009). Fostering transformative learning. In Mezirow, J., Taylor, E. and Associates (Eds.), Transformative learning in learning in practice: Insights from community, work place and higher education. San Francisco, CA: Jossey-Bass.

Teaching Tolerance (n.d ). Culture in the classroom. Retrieved from http://www.tolerance.org/print/culture-classroom

Terry, N.P., \& Irving, M.A. (2010). Cultural and linguistic diversity: Issues in Education. Kendall Hunt Publishing Co. Retrieved from https://www.kendallhunt.com/uploadedFiles

Villegas, A.M., \& Lucas, T. (2014). Preparing culturally responsive teachers. Journal of Teacher Education, 53(1), 20-32. http://dx.doi.org/10.1177/0022487102053001003

Wilkins, J., \& Gamble, R. J. (1998). Evaluating multicultural literature for use in the classroom. Educational Considerations, 26(2), 28-31.

Willis, A., \& Johnson, J. (2000). A horizon of possibilities: A critical framework for transforming multiethnic literature instruction. Retrieved from http:www.readingonline.org/articles/willis/index.html

Wyoming. (2007). Just the facts. Retrieved June 18, 2008 from http://eadiv.state.wy.us/Wy_facts/facts07.pdf

York, S. (1991). Roots and wings: Affirming culture in early childhood programs. St. Paul, MI: Redleaf Press. 